\title{
Recurring issues in the IEA, the discipline and the profession of ergonomics/human factors
}

\author{
John R Wilson \\ Human Factors Research Group, Faculty of Engineering, University of Nottingham, Nottingham NG7 2RD, UK
}

\begin{abstract}
Although the past 25 years have seen many apparently new challenges for the academic discipline and the professional practice of ergonomics/human factors, and for the International Ergonomics Association, many issues in fact have recurred over the period. This paper takes the relevant decades and de3scribes the internal and external priorities of the IEA at the time, the main developments for researchers and practitioners, and the author's own professional interests at the time..Such an admittedly partial description of events and priorities could feed into current attempts to strengthen the position of ergonomics/human factors for this and subsequent decades.
\end{abstract}

Keywords: Human factors, ergonomics, International Ergonomics Association, history,

\section{Introduction}

For a contribution to this special session on the last 25 years of the IEA, I look at what was happening in the IEA itself at various relevant times, and in parallel what was happening at the same time within the discipline and the profession of ergonomics/human factors. You don't often get an opportunity to write something like this, where there is little need to cite absolute evidence and where personal memory, perspective and even bias is all. So I am going, to an extent, to be self indulgent (hence the first person singular!) and as well as describing my entirely partial view of what was happening in the worlds of the IEA and of the discipline and profession of E/HF, I will briefly note my own changing journey through the fundamental and applied scientific field.

That this is a personal perspective is clear, and it must be accepted that the memories and records of others will be different, perhaps radically, as will their sense of priorities and importance of issues at the time. The time span actually taken will be from around the 1980 s to the present day, although the 25 year period chosen by the special session organiser is highly appropriate since this author attended his first IEA conference in Toronto in 1984, first IEA Tri- ennial congress in Bournemouth in 1985, and first IEA Council meeting in Vancouver in 1986.

\section{1980s}

For the IEA, and for its federated societies (and I know for a fact for the then Ergonomics Research Society in the UK) this was the decade of concern about the "lost communities", particularly that which over time became human computer interaction. Those who had come from a computer science or cognitive psychology background, working on peoples' thinking and interaction with computer systems, had a mistaken view that ergonomics was to do largely with the physical aspects of life (a misapprehension which still exists for one or two people today!) and so tried to form their own communities. We can see the affect of this 30 years later in the groupings built around usability professionals and CHI (Computer Human Interaction), the latter of which tends largely to consist of computer scientists with an interest in people rather than human scientists with an interest in people's use of computers. Although agonising over the name of the discipline (and by extension its definition) has always been with us, the moves for independence of a nascent 
HCI community meant that in the UK and elsewhere the notion of using the HF rather than the E descriptor for our field became louder for a while.

In this decade the world of human factors became concerned less with individuals interacting with things and more with groups of people at work interacting with processes. The IEA formed collaborations to run conferences with organisations like IFIP and IFAC. This lead to the development of the community concerned with human machine systems, and fairly shortly afterwards, supported in part by funding from NATO, a community built around the idea of cognitive systems engineering. Elsewhere in the IEA, this decade saw the start of the Organisational Design and Management (ODAM) movement by Hal Hendrick and friends and colleagues, linking perhaps not as well as it should have with the growth in understanding of systems ergonomics in Europe, especially France.

From a purely housekeeping point of view the notes from IAE council meetings at the time show that we had strong concern for our financial basis and steps were put in place to do with subscriptions for federated societies and investments that have stood us in reasonable stead to this date.

In the world of science and practice within ergonomics and human factors, the 1980s certainly saw an expansion in contributions to understanding people's use of computer systems and the growth of HCI. Given the development of interest in process control and safety, impelled first of all by the 3 Mile Island incident and then later disasters through the $80 \mathrm{~s}$, the work of the Ris $\varnothing$ laboratory in Denmark and others had enormous influence. A new transdisciplinary community drew from cognitive psychology, cognitive engineering, systems engineering, control theory and human reliability and decision making to develop new theories, models and approaches to understanding human control in process and transport industries, and particularly the influence on human reliability (with particular reference to the nuclear industry).

In a contrasting area of work, some of those who had been working in workplace and physical ergonomics, and in product ergonomics, over the past few years started to promote the approaches and methods of participatory ergonomics and participatory design. This linked really well with the ODAM community and eventually formed groups within the HCI world in the context of user-centred design.

In my own research, work on architectures, developments in buildings, facilities and workplace design at Loughborough and Birmingham extended into much work on participatory ergonomics/design when I moved to Nottingham and became influenced by Nigel Corlett, with the formation of the Institute for Occupational Ergonomics (IOE). My PhD work and research with Stuart Kirk at Loughborough, in product liability, safety and design extended into forming the Product Safety and Testing Group with Beverley Norris. And, working with engineers who were developing clever new machines meant that I became heavily influenced by the cognitive engineering movement with its NATO funded workshops organised by Erik Hollnagel and Dave Woods and its integration of manual and automatic control, cognitive psychology, joint cognitive systems, human reliability and decision making. And the impetus given by the NATO workshops and that community led to spending more years than I care to think chasing the elusive white rabbit that is mental models.

\section{1990s}

The records from the IEA over this decade show a large number of different initiatives, both outward facing and inward facing. It was now that a strong interest in promoting ergonomics within industrially developing countries (and of course a fierce debate about what was meant by IDCs!) took place. This drew in part from a link with the developments in participatory ergonomics in the previous decade. The IEA established relationships, including memoranda of understanding, with bodies such as the World Health Organisation and the International Labour Organisation, connections which are still strong today.

Internally, a considerable effort was spent in the 1990s in codifying our governance, establishing sets of operating rules and procedures. The IEA also took on the Herculean task of defining its own field and discipline, and promoting this through its website. Another initiative was in the area of education and professional practice, including certification, where the IEA produced guidance on what would be required of an appropriate education programme at various levels, what was expected from a professional ergonomist, and what a certification or regulation scheme should do.

Scientifically, ergonomics/human factors showed developments from all the movements of the previous decade. The control theory, human reliability and cognitive engineering communities established new approaches in joint cognitive systems. From parallel work elsewhere the idea of distributed cogni- 
tion and cognition in the wild was established. The sense that understanding and support for decision making in work systems should not be left to people who write algorithms, and that decision making was anyway a very context determined experience rather than something that could be described normatively lead to the growth of the naturalistic decision making community. Extension of concern over major systems reliability failures meant that a large group of ergonomists grew up exploring notions of systems safety (and as the decade ended, systems resilience). In HCI there was a broadening of the field, a recognition that we needed to move from an understanding of interface to that of interaction and an explosion of research as the systems themselves moved from single user- single input device-single screen to multiple inputs, multiple outputs, virtual reality/virtual environments, augmented reality and so on. For physical ergonomics the "epidemic" of musculoskeletal disorders, or RSI as called in the popular press, continued to explode from the 1980s, in some countries (eg Australia) more than others, and better research was carried out in the 1990s than earlier on how to understand this problem. The degree to which the understanding and acceptance that work systems could cause such injury, and the extent to which this and related standards activity has been a positive or negative for our profession, is still hotly debated today! Scientifically, in the cognitive field there was also a lot of development in understanding and development of tools for assessing mental workload and situation awareness.

Perhaps the most significant professional move I made in the 1990s was an accidental one - into the strange world of Virtual Reality and particularly the human factors of interacting with virtual environments, and health and side effects problems, and developing applications for industry, medicine and education. Virtual environments in general and advanced interactive systems more widely have proven to be fertile grounds for ergonomics enquiry ever since. Also in this decade my very early industrial engineering background extended into much work on teams and work organisation generally.

\section{4. $2000 \mathrm{~s}$}

In the 2000s at IEA Councils, concerns were raised by the European societies that the IEA had put a lot of effort into developing ergonomics in IDCs, but what was it doing to promote or protect ergonomic/human factors in long established regions and so- cieties? Therefore, initiatives like the Federation of European Ergonomics Societies were born, though it has to be said without a clear agenda as yet. The work with IDCs turned more into particular projects funded by IEA or by its partners in WHO etc, thus showing practical benefits of an E/HF contribution. A number of special initiatives were set up such as those to do with product design and approvals processes. Also we continued to agonise about what it is that ergonomics/human factors in general offers, and what the IEA in particular offers to the world and to our potential client base.

And of course, the long battles (or at least muted skirmishes) over our name(s) ended up in the title of $\mathrm{HF}$ and $\mathrm{E}$ or $\mathrm{E}$ and HF being used by several of the societies around the world (interestingly almost entirely in native English speaking ones, a fact I have only just noticed as I write this). And certainly in the case of the IEHF and I think for the others, the "and" between the $\mathrm{E}$ and the HF or the HF and the $\mathrm{E}$ was used with a heavy heart due to the tautology it commits us to.

From a scientific perspective, one of the key developments of the decade was the move from understanding of team working into investigations into collaborative work and distributed organisations. In HCI the attention moved towards ubiquitous, pervasive and mobile computing, and the holistic ergonomics approach (embracing physical, cognitive and social interactions) required to investigate use of such systems and support improved design. Design in general embraced very much more the notion of universal or inclusive design, addressing the needs of groups such as the elderly or those with particular difficulties; the emotional aspects of interaction also came to the fore. In the world of human reliability, attention was moved to some extent towards the notion of resilience and/or high reliability organisations, and also a determination to try and use as a base the notion of what is it that makes people successful and error free rather than what is it that makes them commit errors (whether this is internally or externally driven).

For my own work the 2000s can be summed up in the word "rail". Parallels with previous human factors work in ATC (eg with Barry Kirwan) underpinned a very large research programme in rail, in which we at first borrowed theory and methods from other domains and have ended the decade developing our own. The team work and VR research came together in research into collaborative working - in engineering and design. And I developed a stronger interest in two areas I have followed over the years. 
One, through my part-time position at Network Rail, has been user needs and requirements development for large scale systems design. The second, through my work at UNSW in Sydney, has been human factors risk and risk management in projects, public systems and finance as well as in safety.

\section{5. $2010+$}

This is not a session or a paper devoted to predicting the future but more to assessing where we have been in the past 25+ years. However, it is appropriate to end with a couple of thoughts about the issues which are facing us today. Prompted by contributions at a number of Council meetings from a number of federated societies, the IEA is examining the future of ergonomics. This includes what the IEA, its federated societies and all their members might do to better promote what $\mathrm{E} / \mathrm{HF}$ can contribute to the client base (not just governments and funding bodies and industrial clients but also potential entrants into the profession and other professions with which we might cooperate). Of course there is only a short step from doing this to trying to redefine the whole field again, which should be avoided at all costs!. Interestingly, in being involved in this exercise, I have come across files of papers on a number of occasions in the past (for instance the early 1990s) where the IEA embarked on exactly the same exercise for the same reasons.

One of the biggest threats today is to our education programmes. In some universities the view of blinkered and narrow thinking managers is that only large education programmes should be maintained into the future, automatically putting pressure on the usually minority interest ergonomics/human factors programmes around the world. Some of my col- leagues in the ergonomics consultancies, which are still thriving, take the view that any drying up of new entrants from $\mathrm{E} / \mathrm{HF}$ courses does not matter and they themselves will train up new employees with a psychology or engineering background. But this will have the effect of narrowing the potential of the profession to a few approaches and techniques which can be sold today (task analysis, human reliability analysis, safety case, human factors integration etc). More seriously, if the academic discipline dies and profession will not be far behind as E/HF will lose its credibility without university programmes.

The global financial crisis obviously is having an effect in terms of research and application funding available - although it is interesting that where there is investment it is from governments in large infrastructure projects which increasingly require ergonomics contribution in terms of human factors integration, safety case and so on. The financial crisis is also having an impact on the investments of the IEA and the societies themselves, further restricting their room for manoeuvre.

Scientifically, it is perhaps easier to think in terms of advances in application fields rather than in theoretical and fundamental work. In terms of the former, then this decade will probably see the extension of ergonomics/human factors into many of the fields raised, to some scepticism, some $20+$ years ago by Tom Sheridan and Neville Moray amongst others, including our contribution to some of the great problems facing the world today; water shortage (and indeed in the view of some future thinkers water wars); environmental sustainability generally; merged public/private transport technologies; community and government systems etc; and of course health, social services and care systems. 